\title{
Evaluation of Selectivity Changes in HIC Systems Using a Preferential Interaction Based Analysis
}

\author{
Fang Xia, Deepak Nagrath, Shekhar Garde, Steven M. Cramer \\ Howard P. Isermann Department of Chemical Engineering, Rensselaer \\ Polytechnic Institute, Troy, New York 12180-3590; \\ telephone: (518) 276-6198; \\ fax: (518) 276-4030; e-mail: crames@rpi.edu
}

Received 15 July 2003; accepted 16 March 2004

Published online 9 July 2004 in Wiley InterScience (www.interscience.wiley.com). DOI: 10.1002/bit.20120

\begin{abstract}
It is well established that salt enhances the interaction between solutes (e.g., proteins, displacers) and the weak hydrophobic ligands in hydrophobic interaction chromatography (HIC) and that various salts (e.g., kosmotropes, chaotropes, and neutral) have different effects on protein retention. In this article, the solute affinity in kosmotropic, chaotropic, and neutral mobile phases are compared and the selectivity of solutes in the presence of these salts is examined. Since solute binding in HIC systems is driven by the release of water molecules, the total number of released water molecules in the presence of various types of salts was calculated using the preferential interaction theory. Chromatographic retention times and selectivity reversals of both proteins and displacers were found to be consistent with the total number of released water molecules. Finally, the solute surface hydrophobicity was also found to have a significant effect on its retention in HIC systems. (c) 2004 Wiley Periodicals, Inc.

Keywords: preferential interaction; hydrophobic interaction; kosmotropes; chaotropes
\end{abstract}

\section{INTRODUCTION}

Hydrophobic interaction chromatography (HIC) has been shown to have significant utility for the separation of proteins from complex mixtures (Diogo et al., 2000, 2001; Husi and Walkinshaw, 1999; Machold et al., 2003; O'Connor et al., 2000; Pomazal et al., 2002; Sunasara et al., 2003). HIC stationary phases are manufactured by attaching relatively weak hydrophobic functional groups to an agarose or polymer backbone (Queiroz et al., 2001). Accordingly, HIC has milder separation conditions as compared to reversed phase chromatography (RPLC), which minimizes protein denaturation that may occur during the separation process.
The solvophobic and preferential interaction theories have been used to explain the effect of salts on protein binding in HIC systems. The solvophobic theory is based on the association and solvation of the participating species and assumes that the molal surface tension increment of the salt determines solute retention (Melander and Horvath, 1977; Melander et al., 1984, 1989). In the solvophobic theory, it is believed that the cavity is formed and then closed on the stationary and mobile phases, which is not always valid if the salt has a strong interaction with the proteins. Fausnaugh and Regnier (1986) studied the adsorption of several proteins in the presence of different types of salt and found that the solvophobic theory could not adequately explain protein retention differences in the presence of various salts in HIC systems. The preferential interaction theory is based on the interaction between salt and protein, and has been shown to successfully capture the salt type effects in the thermodynamic model (Perkins et al., 1997; Xia et al., 2003). In this work, we apply the preferential interaction theory to study the salt type effects on solute binding and selectivity in HIC systems.

Adsorption in HIC systems is an entropic process which is driven by the release of water molecules from the solute and stationary phase surface (Esquibel-King et al., 1999). In proteins, the surface hydrophobic amino acids accumulate into hydrophobic patches, which are evenly or unevenly distributed on the protein surface. In tandem, there are hydrophobic functional groups attached on the stationary phase ligand surface. Water molecules encircle proteins and ligands individually to form hydrating layers. Under these conditions, we can consider that the hydrophobic parts on the protein and ligand surface are "hidden" beneath the hydrating layers, which shield the interaction between the protein hydrophobic patches and the functionary groups on the ligand surface. Salts are employed in HIC to increase or decrease solute binding. Salt ions that rank differently in the Hofmeister series affect water distributions around the solute and stationary phases to

varying degrees (Pahlman et al., 1977; Porath, 1987).
Correspondence to: S.M. Cramer

Contract grant sponsor: NSF

Contract grant number: BES-9810794 
Anions: $\mathrm{PO}_{4}^{3-}, \mathrm{SO}_{4}^{2-}, \mathrm{CH}_{3} \mathrm{COO}^{-}, \mathrm{Cl}^{-}, \mathrm{Br}^{-}, \mathrm{NO}_{3}^{-}, \mathrm{ClO}_{4}^{-}, \mathrm{I}^{-}, \mathrm{SCN}^{-}$. Cations: $\mathrm{NH}_{4}^{+}, \mathrm{Rb}^{+}, \mathrm{K}^{+}, \mathrm{Na}^{+}, \mathrm{Cs}^{+}, \mathrm{Li}^{+}, \mathrm{Mg}^{2+}, \mathrm{Ca}^{2+}, \mathrm{Ba}^{2+}$.

Increasing salting-in (chaotropic) effect

Kosmotropic salt ions have higher polarity and bind water strongly, which induces the exclusion of water from the protein and ligand surfaces. In contrast, chaotropic salts have less polarity and bind water loosely, which induces inclusion of water on the protein and ligand surfaces. Neutral salts lie in between kosmotropic and chaotropic salts (Arakawa, 1986; Arakawa et al., 1990; Arakawa and Timasheff, 1982, 1984a; Roettger et al., 1989; Porath, 1987).

Salt ions affect water distributions around the solute and stationary phase. As described above, kosmotropic salt binds water tightly and induces the exposure of hydrophobic surfaces on ligands (Collins, 1997; Porath, 1987). In addition, salt ions also have an effect on the hydration of the protein.

Thus, in the presence of these salts the hydrophobic amino acids will interact with the functional groups on the stationary phase surface, forming a protein-ligand complex. After the complex has been formed, the water around the complex will redistribute. Due to the decrease of the hydrophobic exposed surface area, water will be released during the adsorption process. A chaotropic salt is less polar, hence it binds water loosely. Thus, water stays around the protein and stationary phase surfaces, thereby reducing the chance of exposing the hydrophobic surfaces. Accordingly, solute will have less chance to bind to stationary phases. The neutral salt has an intermediate influence on protein binding in HIC systems.

Roettger et al. (1989) first explained the adsorption phenomena from the perspective of the preferential interaction of salt with the solute. Densimetric experiments were conducted to quantify the preferential interaction. In their study, the solute affinities on HIC stationary phases were also found to have a linear relationship with the lyotropic series. Lin et al. $(2000,2001,2002)$ studied the effects of salt, ligand hydrophobicity, and protein structure on the interaction between protein and ligand using microcalorimetric measurement. Byun et al. (2000) explained the salt effects on peptide binding on a SynChropak column and found that a salting-in parameter and a surface tension parameter could be very useful for peptide binding mechanism study. Esquibel-King et al. (1999) studied BSA adsorption under both linear and nonlinear conditions and found that HIC was an entropy-driven process under linear binding conditions. However, under nonlinear conditions enthalpy played some role, but no conclusions could be made at that point. Perkins et al. (1997) compared the effect of the number of water molecules released with salt ions released on protein binding in the HIC system. They found that the number of water molecules released was a major factor in determining protein retention.

In the current study, we employed the approach of Perkins et al. (1997) for a detailed investigation into the effect of salt type on protein and displacer affinity in HIC systems. The total numbers of water molecules and salt ions released during the solute binding process were calculated based on preferential interaction analysis. Solute affinities on HIC resins were found to be consistent with the total number of released water molecules. The effect of different types of salts (kosmotropes, chaotropes, and neutral) on solute binding and elution is elucidated by comparing the total number of released water molecules in the presence of these salts. This work provides insight into the adsorption phenomena and changes in salt selectivity in HIC systems.

\section{THEORY}

Perkins et al. (1997) applied the two-domain model of Timasheff's preferential interaction theory (Arakawa et al., 1990; Arakawa and Timasheff, 1982; Timasheff and Arakawa, 1988) to HIC systems and obtained the capacity factor of a solute in the presence of salt by the following relationships:

For nonelectrolyte:

$$
\ln k^{\prime}=c-\frac{n \cdot \Delta v_{1}}{m_{1} \cdot g} m_{3}+\frac{\left(\Delta v_{+}+\Delta v_{-}\right)}{g} \cdot \ln \left(m_{3}\right)
$$

For electrolyte:

$$
\ln k^{\prime}=c+\left[\frac{\left(\Delta b_{+}+\Delta b_{-}\right)}{g}-\frac{n \cdot \Delta \nu_{1}}{m_{1} \cdot g}\right] m_{3}
$$

where $v_{i}=b_{i} \cdot m_{3}$, and $\Delta b$ is the stoichiometrically weighted change in the ion binding coefficients; $m_{1}$ and $\mathrm{m}_{3}$ are the molal concentration of water and salt, respectively; $g=\left(\frac{\partial \ln m_{3}}{\partial \ln a_{ \pm}}\right)_{T, P}, a$ is the activity of ions; $n$ is the valence of salt ions; $\Delta v_{1}$ is the number of water molecules released during the binding process; $\Delta v_{+}$and $\Delta v_{-}$are the number of cations and anions released during the binding, respectively. Thus, $n$ and $g$ are different for different salt types used in the system. The constant $\mathrm{g}$ can be calculated from the Debye-Huckel equation or from an osmotic pressure experiment. Equation 2 was derived based on the dependence of ion binding on salt concentration.

Equation 1 can be simplified to the following form:

$$
\ln k^{\prime}=\alpha+\beta \cdot m_{3}+\gamma \cdot \ln \left(m_{3}\right)
$$

where $\beta$ and $\gamma$ are called the preferential interaction parameters. The total number of water molecules and salt ions 
released during the binding process can be calculated from the following relationships:

$$
\begin{gathered}
\Delta \nu_{1}=\frac{\beta \cdot g \cdot m_{1}}{n} \\
\Delta \nu_{+}+\Delta \nu_{-}=\gamma \cdot g
\end{gathered}
$$

\section{MATERIALS AND METHODS}

\section{Materials}

Phenyl 650M bulk resin was donated by Tosoh Biosep (Montgomeryville, PA). Phenyl Sepharose (6 FF, high sub) and Butyl Sepharose (4 FF) resins were donated by Amersham Biosciences (Uppsala, Sweden). Sodium phosphate (monobasic), sodium phosphate (dibasic), ammonium sulfate, sodium nitrate, sodium chloride, sodium thiocyanate, and blue dextran $(\mathrm{Mw}=2,000,000)$ were purchased from Sigma (St. Louis, MO). 1,5-naphthalenedisulfonic acid (NDSA), 1-naphthalenesulfonic acid (NSA), caffeine, tartrazine, benzyltributylammonium chloride (BTBAC), sunset yellow, amaranth, phenylacetic acid, and orange G were purchased from Aldrich (Milwaukee, WI). 8-Hydroxypyrene-1,3,6-trisulfonic acid trisodium salt (HPTSA) was purchased from Fluka (Buchs, Switzerland). 1,3,6,8Pyrene tetra sulfonic acid (PTSA) was purchased from Molecular Probes (Eugene, OR). Big Chap was purchased from Calbiochem (La Jolla, CA). Benzoic acid was purchased from Sigma. Lysozyme (hen egg white), lectin (Arachis hypogaea, peanut), trypsinogen (bovine pancreas), ovalbumin, $\alpha$-amyloglucosidase (Aspergillus niger) ( $\alpha$ AMYLASE), asparaginase (Escherichia coli), lysozyme (turkey egg), $\alpha$-chymotrypsinogen A, $\gamma$-globulin (bovine), protease nagarse, protease carlsberg, $\alpha$-chymotrypsin, $\beta$ chymotrypsin, $\gamma$-chymotrypsin, conalbumin, $\alpha$-lactalbumin, human serum albumin, bovine serum albumin, $\beta$-lactoglobulin A, $\beta$-lactoglobulin B, lipoxydase, catalase (bovine liver), adenosine deaminase, lipase (Mucor Miehei), trypsinogen inhibitor, apoferritin (horse spleen), calcineurin (bovine brain), ferrittin type I (horse spleen), cellulase, and lactoferrin were purchased from Sigma. Pyruvate kinase and xylanase were purchased from Fluka. Glutamic oxalacetic transminase was purchased from ICN Biomedicals (Aurora, $\mathrm{OH}$ ).

\section{Apparatus}

Analytical scale isocratic and linear gradient experiments were conducted to obtain protein retention data in the presence of various salts. The experiments were carried out using a chromatographic system from Waters (Milford, MA), which consisted of a 600E Multi-solvent Delivery System, a PDA 996 photodiode array detector, and a 712 WISP autosampler with a cooling module.

\section{Procedures}

To obtain the protein isocratic retention data, the phenyl $650 \mathrm{M}$ column $(90 \times 5 \mathrm{~mm}$ I.D. $)$ column was initially equilibrated with five column volumes of the carrier buffer $100 \mathrm{mM}$ phosphate, $\mathrm{pH}$ 7.0, containing various concentration (ranging from $0.1-1.4 \mathrm{M}$ ) of working salt (ammonium sulfate, sodium chloride, or sodium thiocyanate). Small amounts of proteins were then injected into the HIC column and the protein retention time was determined. The column was then equilibrated with the next working buffer for about five column volumes until the next injection was made. This process was repeated to obtain the duplicate data for each retention time. The column effluent was monitored by PDA detector between the wavelength ranges of 200-300 $\mathrm{nm}$. Flow rate was maintained $0.5 \mathrm{ml} / \mathrm{min}$ $(153 \mathrm{~cm} / \mathrm{h})$. All experiments were carried out in duplicate at room temperature.

To obtain the protein linear gradient retention data, the phenyl $650 \mathrm{M}$ column $(90 \times 5 \mathrm{~mm}$ I.D. $)$ column was initially equilibrated with five columns volume of the carrier buffer $100 \mathrm{mM}$ phosphate, $\mathrm{pH} 7.0$, containing $1.4 \mathrm{M}$ ammonium sulfate or $4.2 \mathrm{M}$ sodium chloride. Then a small amount of protein was injected into the HIC column and a 90-min linear gradient was conducted to $100 \mathrm{mM}$ phosphate buffers, $\mathrm{pH}$ 7.0. The protein retention time was recorded to indicate its affinity on HIC resin in the presence of different types of salt. All experiments were carried out in duplicate at room temperature.

The total delay volumes of the system, which included the interstitial volume, the tubing volume, and the void volumes of column endings and detector, were measured by the retention time of pulse injection of blue dextran at low flow rate. The effluent was monitored at $254 \mathrm{~nm}$ by a PDA detector. The retention time $\left(t_{0}\right)$ of unretained tracer (sodium nitrate) was also determined for capacity factor $\left(k^{\prime}\right)$ calculation. The column effluent was monitored at $310 \mathrm{~nm}$ to obtain the nitrate absorbance data.

\section{RESULTS AND DISCUSSION}

Designing a selective HIC process is a challenging task for chromatographers. The selectivity of the HIC chromatographic process is influenced by many factors, such as mobile phase additives, salt types, $\mathrm{pH}$, and displacer (for HIC displacement separations). Among these factors, salt types play an important role. In this work, we study the effect of salt types on protein selectivity in determining the number of water molecules released using the preferential interaction theory of Perkins et al. (1997).

Thirty-five proteins were selected for their diversity in crystal structures obtained from the Protein Data Bank (PDB). In addition, 12 small molecule displacers were selected based on their diversity in chemical structure properties. The various types of salts used in this study were selected based on their positions in the Hofmeister (lyotropic) series (Pahlman et al., 1977; Porath, 1987). 
$\left(\mathrm{NH}_{4}\right)_{2} \mathrm{SO}_{4}$ was selected as a representative kosmotrope salt, $\mathrm{NaCl}$ as a neutral salt, and $\mathrm{NaSCN}$ as a chaotrope salt. Based on the Debye-Huckel equation, the total ionic strength is calculated by $I=0.5 \sum m_{i} Z_{i}^{2}$, where $\mathrm{m}$ and $\mathrm{Z}$ denote the molarity and valency for both anions and cations. Accordingly, in this work we employed constant total ionic strength (e.g., ammonium sulfate was one-third that of sodium chloride and sodium thiocyanate) in experiments.

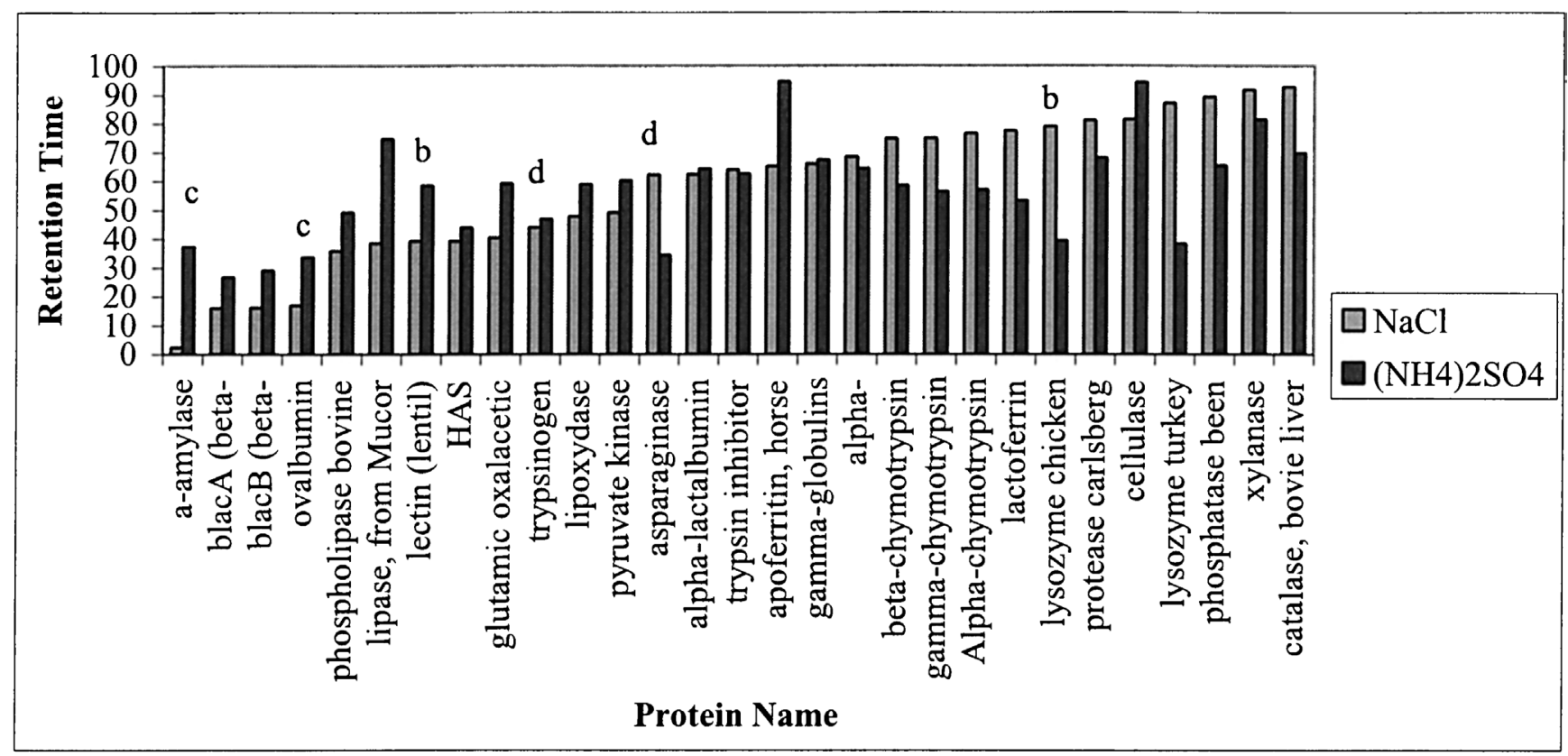

(1a)

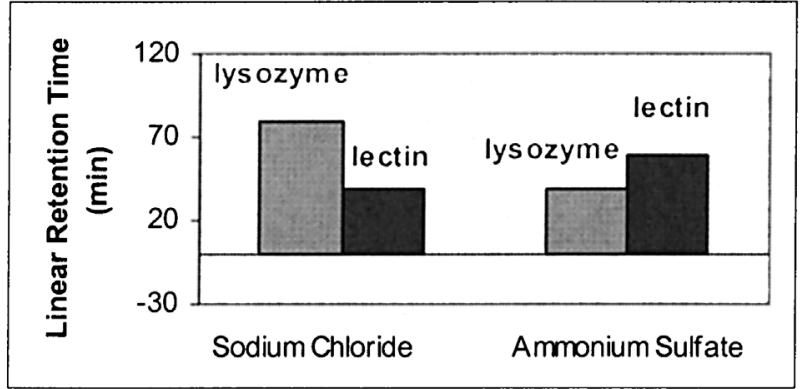

(1b)

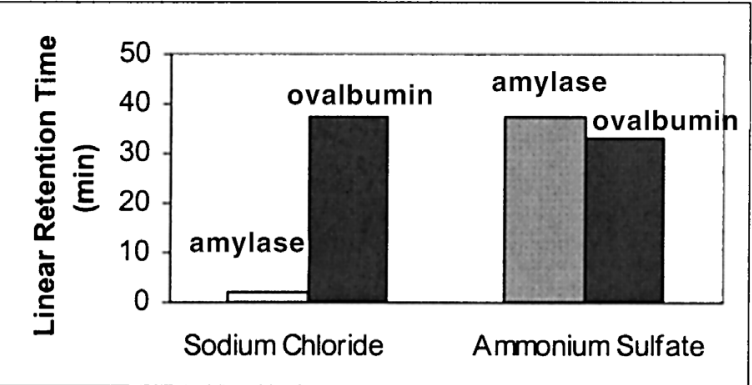

(1c)

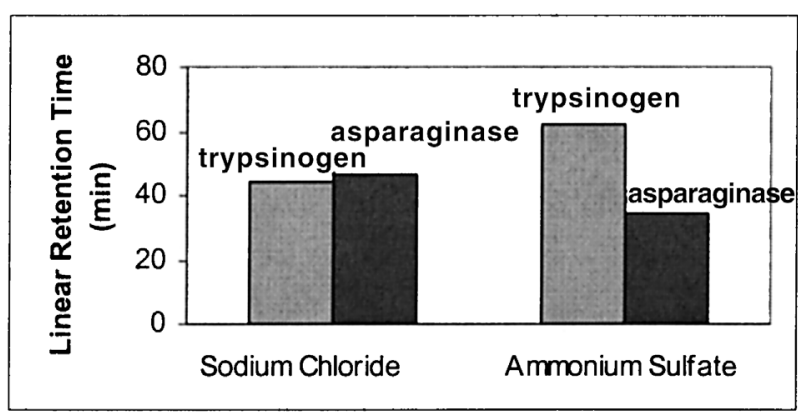

(1d)

Figure 1. Linear gradient retention data of different proteins on phenyl $650 \mathrm{M}$ resin in the presence of sodium chloride and ammonium sulfate. Mobile phase: $0.1 \mathrm{M}$ phosphate buffer at $\mathrm{pH}$ 7. 90 -min linear gradient from $1.4 \mathrm{M}$ ammonium sulfate to $0 \mathrm{M}$; or $4.2 \mathrm{M}$ sodium chloride to $0 \mathrm{M}$. a: Comparison of proteins retention time in presence of various salt. b-d: protein pair affinity selectivity reversals in presence of two salts; (b) lysozyme and lectin, (c) amylase and ovalbumin, (d) trypsinogen and asparaginase. 


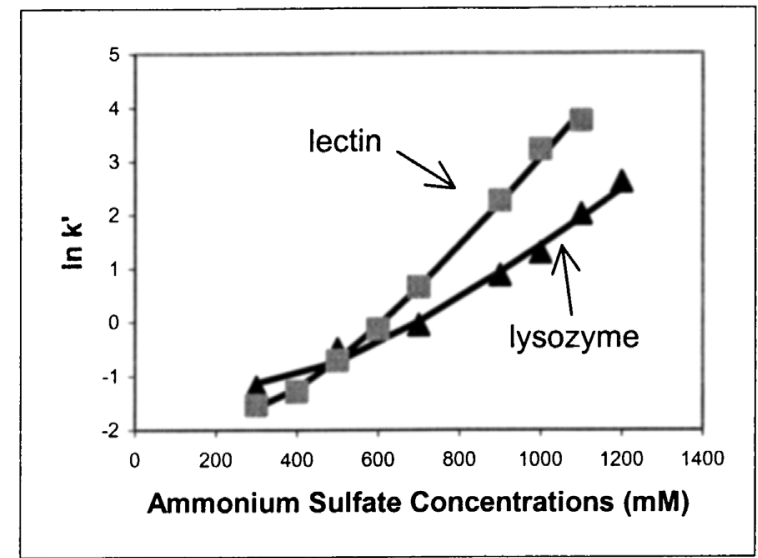

(2a)



$(2 \mathrm{c})$

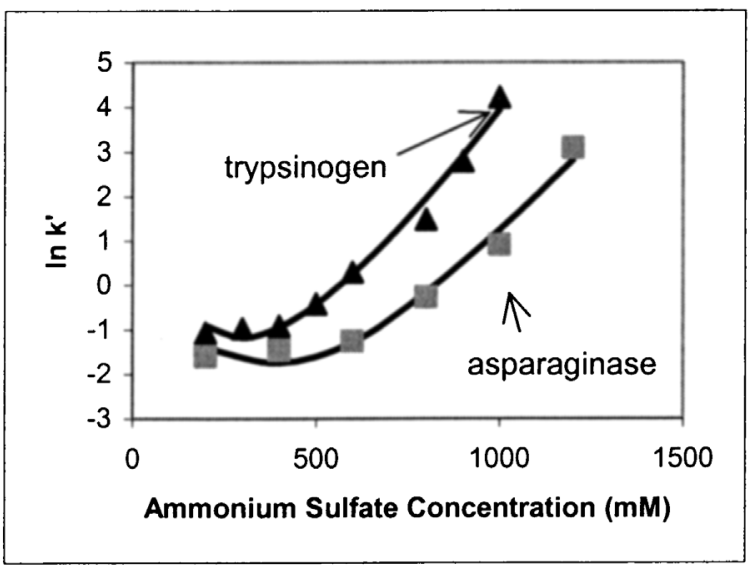

(2e)

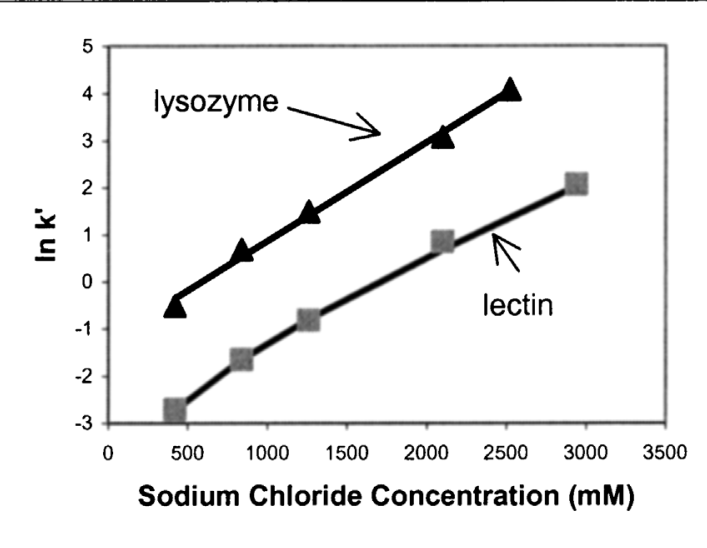

$(2 b)$

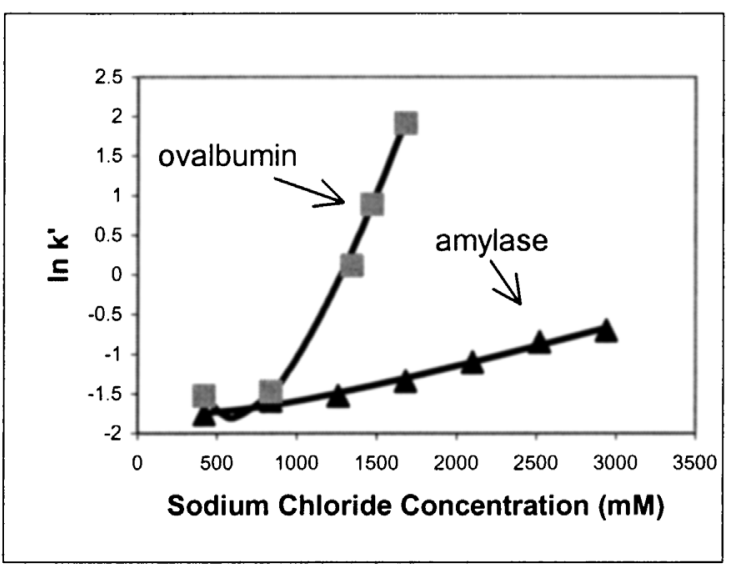

(2d)

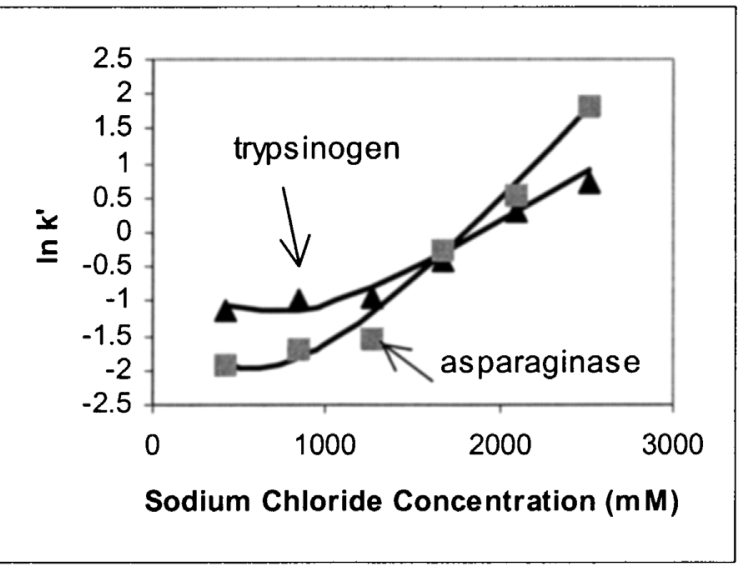

(2f)

Figure 2. Comparison of retention time of protein pairs in Figure 1 in the presence of ammonium sulfate and sodium chloride. a,c,e: In the presence of ammonium sulfate. b,d,f: In the presence of sodium chloride. a,b: Lysozyme and lectin. c,d: Amylase and ovalbumin. e,f: Trypsinogen and asparaginase. Lines are optimized results using Eq. 2.

In this article we first examine the selectivity of a large number of proteins using linear gradient chromatography with two different salt types. Protein pairs which exhibit interesting selectivity changes are then selected for detailed analysis using isocratic chromatography and preferential interaction analysis. Finally, we examine the effect of surface hydrophobicity on both protein and displacer affinity in HIC systems. 
Linear gradient retention data of 35 proteins (to identify protein pairs) on the phenyl $650 \mathrm{M}$ resin in the presence of $\left(\mathrm{NH}_{4}\right)_{2} \mathrm{SO}_{4}$ and $\mathrm{NaCl}$ are shown in Figure 1a. The retention data are arranged in ascending order based on sodium chloride. Clearly, when the salt type is changed from $\left(\mathrm{NH}_{4}\right)_{2} \mathrm{SO}_{4}$ to $\mathrm{NaCl}$ the proteins' retention data showed significant differences. The selectivity changes of three protein pairs in the presence of $\left(\mathrm{NH}_{4}\right)_{2} \mathrm{SO}_{4}$ or $\mathrm{NaCl}$ are illustrated in Figure $1 \mathrm{~b}-\mathrm{d}$. As seen in Figure $1 \mathrm{~b}$, while lysozyme has a higher retention time than lectin in the presence of $\mathrm{NaCl}$, it has a lower retention in the presence of $\left(\mathrm{NH}_{4}\right)_{2} \mathrm{SO}_{4}$. These results demonstrate that selectivi- ty reversals exist when proteins are exposed to different types of salt. Similarly, the elution reversals between $\alpha$ amyloglucosidase and ovalbumin are observed in Figure 1c and between trypsinogen and asparaginase in Figure 1d.

Isocratic experiments were then conducted to obtain capacity factors data at various salt concentrations in the presence of ammonium sulfate, sodium chloride, and sodium thiocyanate for the three protein pairs shown in Figure $1 \mathrm{~b}-\mathrm{d}$. A comparison of the $\ln k^{\prime}$ vs. salt concentration plots for the three protein pairs in the presence of ammonium sulfate and sodium chloride are presented in Figure 2. While there is a selectivity reversal at high salt

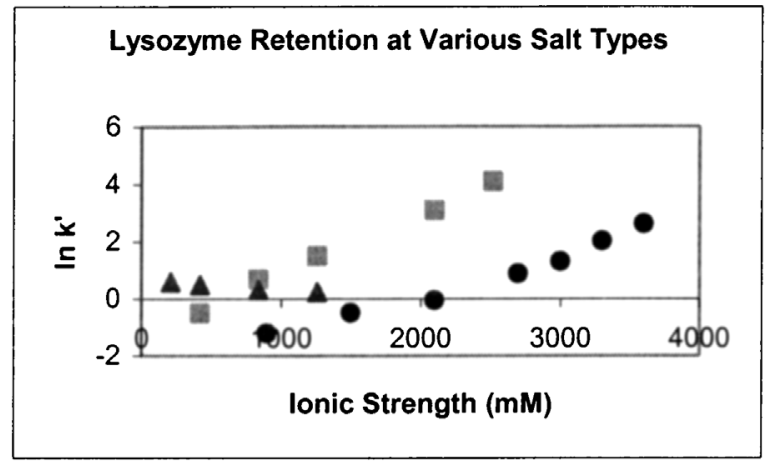

(3a) lysozyme

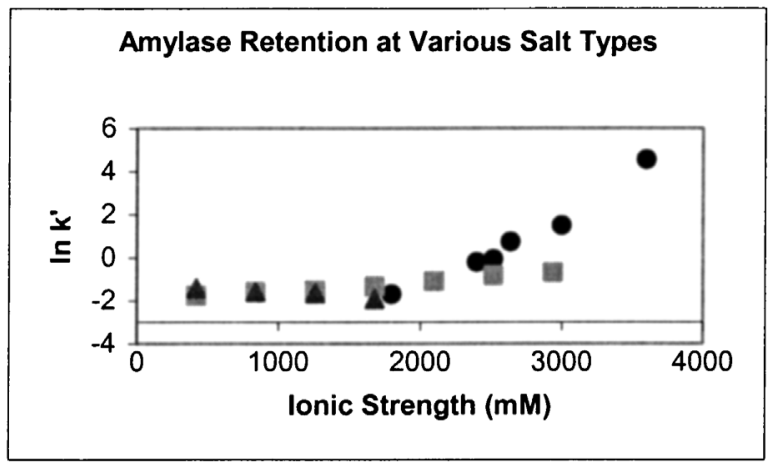

(3c) $\alpha$-amyloglucosidase (amylase)

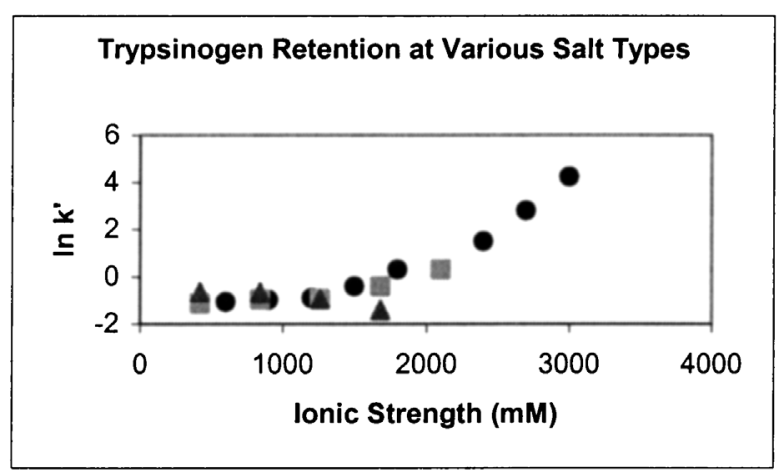

(3e) trypsinogen

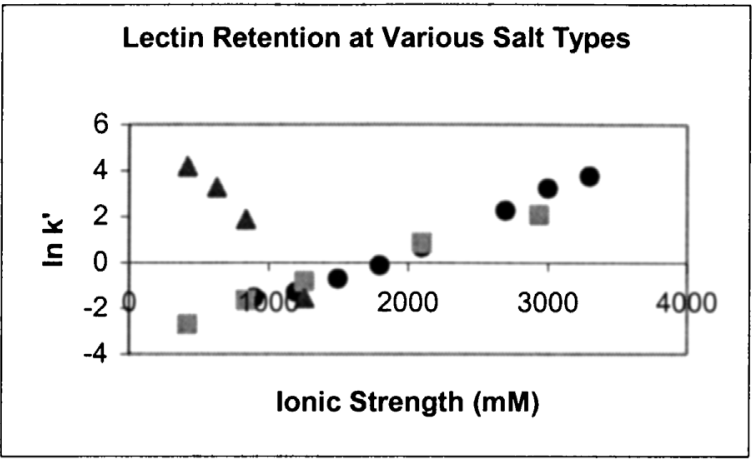

(3b) lectin

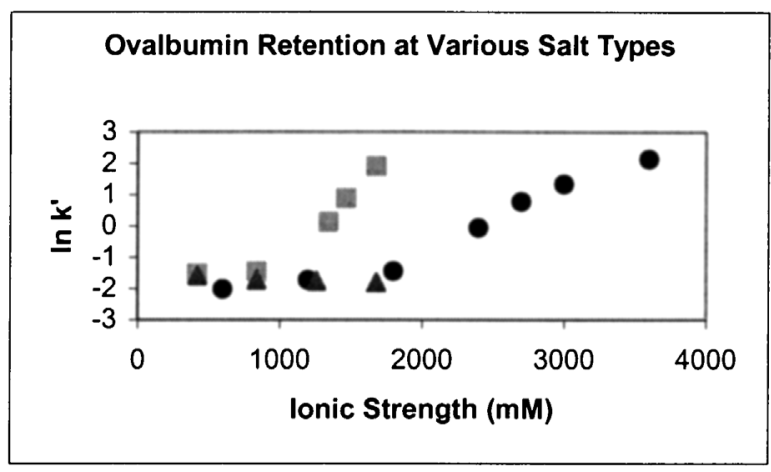

(3d) ovalbumin

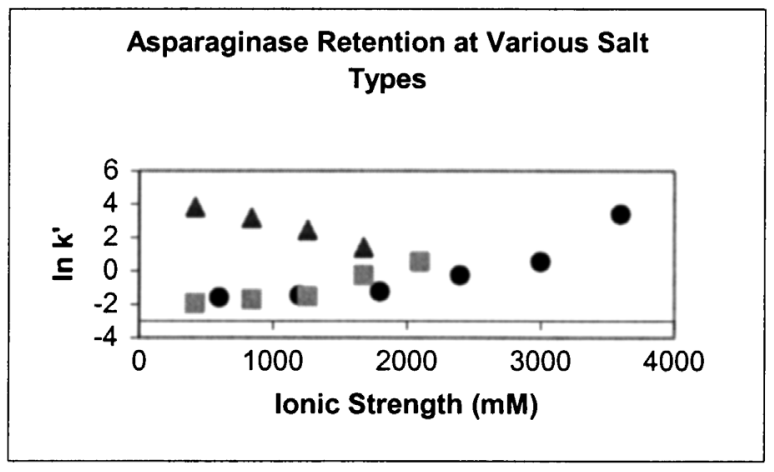

(3f) asparaginase

Figure 3. Comparison of protein retention time in the presence of various salt types. a: Lysozyme. b: Lectin. c: Amylase. d: Ovalbumin. e: Trypsinogen. f: Asparaginase. $(\bullet)$, ammonium sulfate; $(\boldsymbol{\square})$, sodium chloride; ( $\mathbf{\Delta})$, sodium thiocyanate. 
for each protein pair, there is a significant difference in the behavior of the $\ln k^{\prime}$ plots. While lysozyme, lectin, and amylase exhibited linear $\ln k^{\prime}$ plots in the presence of sodium chloride, the other proteins exhibited nonlinear plots. Further, all proteins exhibited nonlinear plots (with the possible exception of lectin) in the presence of ammonium sulfate. Several of the $\ln k^{\prime}$ plots crossed, indicating selectivity reversals at different salt concentrations.

In order to examine these salt effects in more detail, a comparison of the six proteins capacity factor changes in the presence of $\left(\mathrm{NH}_{4}\right)_{2} \mathrm{SO}_{4}, \mathrm{NaCl}$, and $\mathrm{NaSCN}$ are shown in Figure 3. Proteins are arranged in the order of lysozyme, lectin, $\alpha$-amyloglucosidase, ovalbumin, trypsinogen, and asparaginase. In Figure $3 \mathrm{a}-\mathrm{f}$, we can see that the $\ln k^{\prime}$ vs. $C_{\text {salt }}$ variation of these proteins in the presence of different salts has significant differences. In general, proteins' capacity factors increase with the salt concentration increase for the kosmotropic $\left(\left(\mathrm{NH}_{4}\right)_{2} \mathrm{SO}_{4}\right)$ and neutral salt $(\mathrm{NaCl})$, but decrease with the salt concentration increase for the chaotropic salt $(\mathrm{NaSCN})$. As seen in the figures, lectin and asparaginase experience a significant decrease of retention in the presence of $\mathrm{NaSCN}$ when compared with the decrease of retention of other proteins in the presence of NaSCN. However, in the presence of sodium chloride both lysozyme and ovalbumin experience significant increase in retention with an increase in ionic strength.

In order to calculate the total number of released water molecules, Eq. 3 was employed to fit the experimental data in Figure 2a (Xia et al., 2003). The nonlinear retention model parameters $(\alpha, \beta$, and $\gamma)$ for lysozyme and lectin are listed in Table I. The total number of released water molecules $\left(-\Delta v_{1}\right)$ and the total number of released salt ions $\left(-\left(\Delta v_{+}+\Delta v_{-}\right)\right)$were calculated based on Eqs. 4 and 5. As seen in the table, the value of $\left(-\Delta v_{1}\right)$ is significantly higher than the value of $-\left(\Delta v_{+}+\Delta v_{-}\right)$for both proteins, which is consistent with previous results in the literature (Esquibel-King et al., 1999; Perkins et al., 1997).

Since the protein retention is dominated by the release of water molecules, Eqs. 3-5 were used to fit the protein isocratic experimental data in the presence of various types of salts and the calculated total number of released water molecules for the six proteins are presented in Table II. As

Table I. Summary of the total number of released water and salt ion molecules per bound protein molecule calculated from Eqs. 4 and 5 .

\begin{tabular}{lcc}
\hline & Lysozyme & Lectin \\
\hline$\alpha$ & 8.16 & 10.20 \\
$\beta$ & 0.0071 & 0.011 \\
$\gamma$ & -2.00 & -2.66 \\
$-\Delta v_{l}$ & 221 & 348 \\
$-\left(\Delta v_{+}+\Delta v_{-}\right)$ & 1.2 & 1.6 \\
\hline
\end{tabular}

Preferential interaction parameters $(\alpha, \beta$, and $\gamma)$ were obtained from parameter fitting of Eq. 3 with isocratic experiments results (Xia et al. 2003). The $\mathrm{n}$ and $\mathrm{g}$ values used to calculate $-\Delta v_{1}$ and $-\left(\Delta v_{+}+\Delta v_{-}\right)$are 3 and 1.7 , respectively. seen in the table, for most of the proteins the values of total number of released water molecules decrease in the order of kosmotropic $>$ neutral $>$ chaotropic salt. As discussed above, the highly polar kosmotropic ions bind water tightly and induce water release upon binding; chaotropic ions bind water loosely and break water structure. Therefore, a decrease in released water molecules is expected when salt polarity decreases from kosmotropes to chaotropes. In the presence of $\left(\mathrm{NH}_{4}\right)_{2} \mathrm{SO}_{4}$, the total number of released water molecules of lysozyme $\left(\left(-\Delta v_{1}\right)=221\right)$ was smaller than that of lectin $\left(\left(-\Delta v_{1}\right)=348\right)$. While in the presence of $\mathrm{NaCl}$, the total number of released water molecules of lysozyme $\left(\left(-\Delta v_{1}\right)=121\right)$ is larger than that of lectin $\left(\left(-\Delta v_{1}\right)=57\right)$. As was observed from the linear gradient data in Figure $1 \mathrm{~b}$ and the isocratic $\ln k^{\prime}$ data in Figure $2 \mathrm{a}, \mathrm{b}$, lysozyme has a lower affinity than lectin in $\left(\mathrm{NH}_{4}\right)_{2} \mathrm{SO}_{4}$, but a higher affinity in $\mathrm{NaCl}$. These results show that the total number of released water molecules is consistent with the protein elution order in the presence of these two types of salts. Similarly, the total number of released water molecules for trypsinogen, asparaginase, $\alpha$-amyloglucosidase, and ovalbumin are also calculated in Table II. In the presence of $\left(\mathrm{NH}_{4}\right)_{2} \mathrm{SO}_{4}$, the total number of released water molecules was higher for trypsinogen $\left(\left(-\Delta v_{1}\right)=457\right)$ than for asparaginase $\left(\left(-\Delta v_{1}\right)=361\right)$. On the other hand, in the presence of $\mathrm{NaCl}$, the total number of released water molecules for trypsinogen $\left(\left(-\Delta v_{1}\right)=92\right)$ was larger than that of asparaginase $\left(\left(-\Delta v_{1}\right)=36\right)$. Again, the numbers of released water molecules was consistent with the two protein's elution order in the presence of these two salts. Similar results were also observed for $\alpha$-amyloglucosidase and ovalbumin. In contrast to the results obtained with ammonium sulfate and sodium chloride, the total numbers of water molecules released for all proteins in the presence of sodium thiocyanate were negative. This indicates that the water density on the proteins' surfaces are higher in the adsorbed state than in bulk solution. These results are consistent with the physical properties of chaotropic salts as described by Roettger et al. (1989). Thus, the results shown in Table II and Figures 1-3 indicate that the effect of salts

Table II. List of total number of released water molecules for various proteins in the presence of various salts calculated form Eq. 4.

\begin{tabular}{lccl}
\hline & \multicolumn{3}{c}{$-\Delta v_{1}$} \\
\cline { 2 - 4 } \multicolumn{1}{c}{ Protein names } & $\left(\mathrm{NH}_{4}\right)_{2} \mathrm{SO}_{4}$ & $\mathrm{NaCl}$ & $\mathrm{NaSCN}$ \\
\hline Lysozyme & 221 & 121 & -55 \\
Lectin & 348 & 57 & -205 \\
Trypsinogen & 457 & 92 & -75 \\
Asparaginase & 361 & 136 & -120 \\
$\alpha$-Amyloglucosidase & 420 & 26 & -5 \\
Ovalbumin & 372 & 359 & -25 \\
\hline
\end{tabular}

The $\mathrm{n}$ and $\mathrm{g}$ values used for $-\Delta v_{1}$ calculations are as follows: for ammonium sulfate, $\mathrm{n}$ and $\mathrm{g}$ are 3 and 1.7, respectively; for sodium chloride, $\mathrm{n}$ and $\mathrm{g}$ are 2 and 1.6, respectively; for sodium thiocyanate, $\mathrm{n}$ and $\mathrm{g}$ are 2 and 1.5 , respectively. 
on protein affinity in HIC systems can be explained by differences in the total number of released water molecules induced by different types of salts.

In fact, the effect of salt type on protein retention in HIC systems is similar to the salt type effects observed for hydrophobic interactions of proteins in free solution (Arakawa and Timasheff, 1984b; Collins, 1997; Fausnaugh and Regnier, 1986; Jelesarov et al., 1998). In free solutions, while the chaotropic salts stabilize proteins by preferentially hydrating the protein surface, kosmotropic salts strengthen the hydrophobic interactions. Unlike the salt effects on proteins in free solution, the stationary phase ligands are also involved in the chromatographic process. Kosmotropes exclude water from the protein and the resin surfaces, thereby increasing the hydrophobic interactions between them. Thus, salts selectivity in HIC can be understood as differences in their capabilities to exclude water from the protein and the resin surface. These results indicate that the calculation of the total number of released water molecules is a combined effect of salt on protein and resin surfaces.

Figure 4 presents a plot of the total number of released water molecules vs. the protein linear retention data (Fig. 1a) in the presence of $\mathrm{NaCl}$. One can observe from Figure 4 that the proteins' linear retention time increases as the total number of released water molecules increase, with the exception of ovalbumin, which shows a relatively low retention time and a relatively high number of released water molecules. One possible explanation for this discrepancy with ovalbumin is that it has a relatively homogeneous distribution of hydrophobic amino acids on its surface as compared to the other proteins. Obviously, this is just conjecture at this point, and a more detailed study of the effect of hydrophobic amino acid distributions on the protein retention in HIC systems is under way and will be the subject of a future article.

Previous work from our laboratory has indicated that low molecular mass displacers may have significant utility as displacers for the purification of proteins in HIC systems (Shukla et al., 2000a,b; Sunasara et al., 2003). Accordingly, it was of interest to study the relationship of the number of released water molecules to displacer affinity in HIC



Figure 4. Linear retention time of proteins vs. number of water molecule released during the binding process in the presence of sodium chloride.

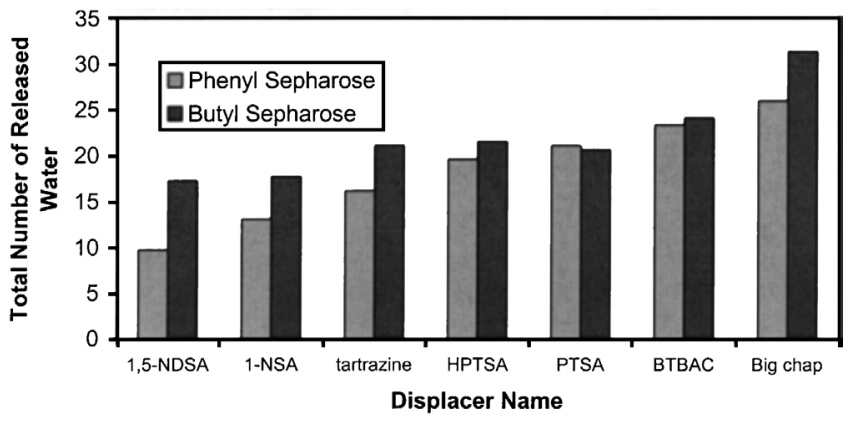

Figure 5. Column hydrophobicity effects on the total number of released water molecules for various small molecular weight displacers on two HIC resins.

systems. The isocratic and linear gradient retention data of several low molecule mass displacers on butyl and phenyl Sepharose columns in the presence of ammonium sulfate was determined. The total numbers of released water molecules $\left(-\Delta v_{1}\right)$ were then calculated for the butyl Sepharose and phenyl Sepharose columns in Figure 5. As seen in the figure, almost all the displacers exhibited a higher number of released water molecules on the butyl Sepharose column than on the phenyl Sepharose column. Because the butyl column has a higher ligand density (50 $\mu \mathrm{mol} / \mathrm{ml}$ bed) than the phenyl column $(25 \mu \mathrm{mol} / \mathrm{ml}$ bed), the total number of released water molecules was found to be consistent with the total hydrophobic area of the resins.

In Figure 6, we compare the total number of released water molecules for the displacers with their linear retention time on the phenyl Sepharose column. As seen in the figure, linear retention times of these molecules were proportional to the released water molecules, with the exception of Big Chap. Big Chap is a nonionic detergent analog of CHAPS and CHAPSO (Xia et al., 2003), which possesses two long alkyl chains with many hydroxyl

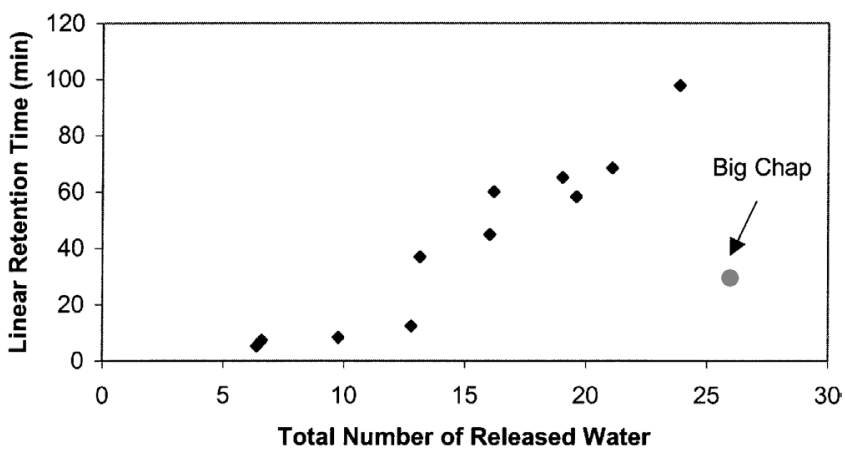

Figure 6. Change of small molecule displacers' linear retention time with the total number of released water molecules on phenyl sepharose column; $100 \mathrm{mM}$ phosphate buffer, $\mathrm{pH} \mathrm{7,} \mathrm{with} \mathrm{various} \mathrm{concentrations}$ of ammonium sulfate. Linear gradient from 1.4 M ammonium sulfate to $0 \mathrm{M}$ in $90 \mathrm{~min}$. Other molecules shown in this plot are as follows (retention time from low to high): phenylacetic acid, benzoic acid, 1,5-NDSA, caffeine, 1-NSA, orange G, HPTSA, tartrazine, sunset yellow, PTSA, and amaranth. 


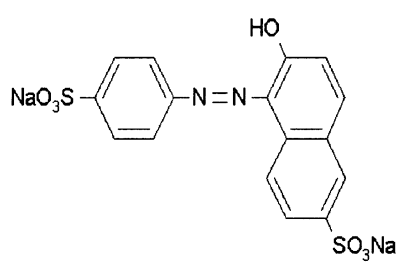

Sunset yellow

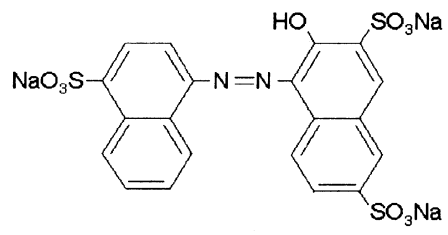

Amaranth<smiles>O=S(=O)(O[Na])c1cccc2c(S(=O)(=O)O[Na])cccc12</smiles>

NDSA<smiles>COS(=O)(=O)c1cc(S(=O)(=O)O)c2ccc3c(S(=O)(=O)O)cc(S(=O)(=O)[O-])c4ccc1c2c43</smiles>

PTSA<smiles>O=S(=O)(O)c1cccc2ccccc12</smiles>

1-NSA<smiles>O=S(=O)(O[Na])c1cc(O)c2ccc3c(S(=O)(=O)O[Na])cc(S(=O)(=O)O[Na])c4ccc1c2c34</smiles>

HPTSA

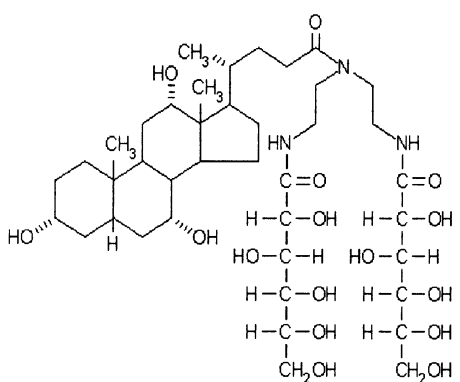

Big Chap

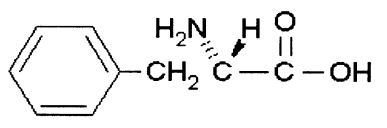

Phe<smiles>O=C(O[Na])c1nn(-c2ccc(S(=O)(=O)O[Na])cc2)c(O)c1N=Nc1ccc(S(=O)(=O)O[Na])cc1</smiles>

Tartrazine<smiles>O=[N+]([O-])c1cc(S(=O)(=O)O)cc2ccc(O)c(N=Nc3ccccc3)c12</smiles>

Orange G<smiles>O=C(O)Cc1ccccc1</smiles>

Benzoic acid<smiles>Cn1c(=O)c2c(ncn2C)n(C)c1=O</smiles>

Caffeine

Figure 7. Chemical structures of the small molecule displacers studies.

groups. Therefore, Big Chap tends to be a more hydrophilic molecule with a $\log \mathrm{P}$ (octanol-water partition coefficient) value of -5.37 . Thus, the interaction between the hydroxyl groups on Big Chap with the hydrophilic resin backbone of the sepharose material might also be contributing to its overall affinity. The chemical structures of these small molecule displacers are listed in Figure 7.

\section{CONCLUSIONS}

In this article, protein affinity in HIC systems in the presence of kosmotropic, neutral, and chaotropic salts was investigated. Linear gradient chromatography was used to identify protein pairs that exhibited selectivity reversals. Isocratic experiments were then carried out to determine the $\ln k^{\prime}$ - salt plots for these particular proteins. The total number of released water molecules during the solute binding process was then calculated based on the preferential interaction theory and the results were found to be consistent, in general, with protein affinity in these HIC systems. A similar study was also carried out with low molecular mass displacers and the results indicated that the total numbers of released water molecules during displacer binding were also consistent, in general, with displacer affinity in these systems. Further, the number of water molecules released upon binding to the butyl Sepharose material were consistently higher than those obtained for the phenyl Sepharose material. While these results demonstrate that binding affinity in HIC systems can be interpreted using the preferential interaction theory, more work is required to obtain a more detailed understanding of the many parameters that can affect selectivity in HIC systems. 
This work was funded by NSF grant BES-0214183. HIC resins were donated by Amersham Biosciences (Uppsala, Sweden) and Tosoh Biosep (Montgomeryville, PA).

\section{References}

Arakawa T. 1986. Thermodynamic analysis of the effect of concentrated salts on protein interaction with hydrophobic and polysaccharide columns. Arch Biochem Biophys 248:101-105.

Arakawa T, Timasheff SN. 1982. Preferential interactions of proteins with salts in concentrated-solutions. Biochemistry 21:6545-6552.

Arakawa T, Timasheff SN. 1984a. Mechanism of protein salting in and salting out by divalent-cation salts - balance between hydration and salt binding. Biochemistry 23:5912-5923.

Arakawa T, Timasheff SN. 1984b. Protein stabilization and destabilization by guanidinium salts. Biochemistry 23:5924-5929.

Arakawa T, Bhat R, Timasheff SN. 1990. Preferential interactions determine protein solubility in 3-component solutions - the $\mathrm{MgCl}_{2}$ system. Biochemistry 29:1914-1923.

Collins K. 1997. Charge density-dependent strength of hydration and biological structure. Biophys J 72:65-76.

Diogo MM, Queiroz JA, Monteiro GA, Martins SAM, Ferreira GNM, Prazeres DMF. 2000. Purification of a cystic fibrosis plasmid vector for gene therapy using hydrophobic interaction chromatography. Biotechnol Bioeng 68:576-583.

Diogo MM, Queiroz JA, Prazeres DMF. 2001. Studies on the retention of plasmid DNA and Escherichia coli nucleic acids by hydrophobic interaction chromatography. Bioseparation 10:211-220.

Esquibel-King MA, Dias-Cabral AC, Queiroz JA, Pinto NG. 1999. Study of hydrophobic interaction adsorption of bovine serum albumin under overloaded conditions using flow microcalorimetry. J Chromatogr A $865: 111-122$.

Fausnaugh JL, Regnier FE. 1986. Solute and mobile phase contributions to retention in hydrophobic interaction chromatography of proteins. J Chromatogr 359:131-146.

Husi H, Walkinshaw MD. 1999. Separation of human vitamin Kdependent coagulation proteins using hydrophobic interaction chromatography. J Chromatogr B 736:77-88.

Jelesarov I, Dürr E, Thomas RM, Bosshard AHR. 1998. Salt effects on hydrophobic interaction and charge screening in the folding of a negatively charged peptide to a coiled coil (leucine zipper). Biochemistry 37:7539-7550.

Lin FY, Chen WY, Ruaan RC, Huang HM. 2000. Microcalorimetric studies of interactions between proteins and hydrophobic ligands in hydrophobic interaction chromatography: effects of ligand chain length, density and the amount of bound protein. J Chromatogr A 872:37-47.

Lin FY, Chen WY, Hearn MTW. 2001. Microcalorimetric studies on the interaction mechanism between proteins and hydrophobic solid surfaces in hydrophobic interaction chromatography: effects of salts, hydrophobicity of the sorbent, and structure of the protein. Anal Chem 73:3875-3883.

Lin FY, Chen WY, Hearn MTW. 2002. Thermodynamic analysis of the interaction between proteins and solid surfaces: application to liquid chromatography. J Mol Recog 15:55-93.

Machold C, Deinhofer K, Hahn R, Jungbauer A. 2003. Hydrophobic interaction chromatography of proteins. I. Comparison of selectivity. J Chromatogr A 972:3-19.

Malmquist G, Lundell N. 1992. Characterization of the influence of displacing salts on retention in gradient elution ion-exchange chromatography of proteins and peptides. J Chromatogr 627:107-124.

Melander W, Horvath CS. 1977. Salt effects on hydrophobic interactions in precipitation and chromatography of proteins: an interpretation of the lyotropic series. Arch Biochem Biophys 183:200-215.

Melander W, Corradini D, Horvath CS. 1984. Salt-mediated retention of proteins in hydrophobic-interaction chromatography: application of solvophobic theory. J Chromatogr 317:67-85.

Melander W, El Rassi Z, Horvath CS. 1989. Interplay of hydrophobic and electrostatic interactions in biopolymer chromatography. J Chromatogr 469:3-27.

O'Connor KC, Ghatak S, Stollar BD. 2000. Use of hydrophobic interaction chromatography to separate recombinant antibody fragments from associated bacterial chaperone protein GroEL. Anal Biochem 278: $239-241$.

Pahlman S, Rosengren J, Hjerten S. 1977. Hydrophobic interaction chromatography on uncharged Sepharose derivatives. Effect of neutral salts on the adsorption of proteins. J Chromatogr A 131:99-108.

Perkins TW, Mak DS, Root TW, Lightfoot EN. 1997. Protein retention in hydrophobic interaction chromatography: modeling variation with buffer ionic strength and column hydrophobicity. J Chromatogr A 766:1-14.

Pomazal K, Prohaska C, Steffan I. 2002. Hydrophobic interaction chromatographic separation of proteins in human blood fractions hyphenated to atomic spectrometry as detector of essential elements. J Chromatogr A 960:143-150.

Porath J. 1987. Metal ion-hydrophobic, thiophilic and II-electron governed interactions and their application to salt-promoted protein adsorption chromatography. Biotechnol Prog 3:14-21.

Queiroz JA, Tomaz CT, Cabral JMS. 2001. Hydrophobic interaction chromatography of proteins. J Biotechnol 87:143-159.

Roettger BF, Myers JA, Ladisch MR, Regnier FE. 1989. Adsoprtion phenomena in hydrophobic interaction chromatography. Biotechnol Prog 5:79-88.

Shukla A, Sunasara KM, Rupp RG, Cramer SM. 2000a. Hydrophobic displacement chromatography of proteins. Biotechnol Bioeng 68: $672-680$.

Shukla AA, Deshmukh RR, Moore JA, Cramer SM. 2000b. Purification of oligonucleotides by high affinity, low molecular weight displacers. Biotechnol Prog 16:1064-1070.

Sunasara KM, Xia F, Gronke RS, Cramer SM. 2003. Application of hydrophobic interaction displacement chromatography for an industrial protein purification. Biotechnol Bioeng 82:330-339.

Timasheff SN, Arakawa T. 1988. Mechanism of protein precipitation and stabilization by co-solvents. J Cryst Growth 90:39-46.

Xia F, Nagrath D, Cramer SM. 2003. Modeling of adsorption in HIC systems using a preferential interaction quadratic isotherm. J Chromatogr A 989:47-54. 